\title{
Program Pencegahan Dan Pengendalian Healthcare Associated Infections (HAIs) di Rumah Sakit X Yogyakarta
}

\section{Programme Prevention and Control Healthcare Associated Infections (HAIs) in Hospital X Yogyakarta}

\author{
Totok Sundoro ${ }^{1}$ \\ Prodi Kesehatan Masyarakat, STIKES Surya Global Yogyakarta \\ Email : totoksundoro@gmail.com
}

\begin{abstract}
Background: Nosocomial infections or Health-care Associated Infections (HAIs) are infections that are acquired and develop while the patient is hospitalized. The HAIs / PPI program is important to implement as a measure of the quality of service as well as to protect patients, officers, visitors and families from the risk of contracting infection due to being treated, on duty and visiting hospitals or other health service facilities. Minister of Health Decree No. 129 Regarding Minimum Service Standards in Hospitals, it is explained that the standard incidence of nosocomial infections is $\leq 1.5 \%$, while the incidence rate of infection (phlebitis) in hospitals exceeds the predetermined standard because it is at $6.9 \%$.

Methods: Qualitative research with a descriptive case study design with 4 (four) informants taken by purposive sampling. Collecting data by in-depth interviews, observation and documentation.

Results: The HAIs program that has been implemented includes hand hygiene, infection risk surveillance, periodic risk assessment, PPI training such as hand hygiene campaigns and the use of personal protective equipment (PPE). The hand hygiene compaign program has not been implemented and hand washing compliance by officers has not reached the standard, namely $100 \%$. It is necessary to implement a culture of five-moment hand hygiene, supervision and evaluation for officers / staff through education and supervision carried out by the head of the room, the PPI / IPCN / IPCLN nurses and the hospital PPI committee.

Conclusion: The HAIs Prevention and Control Program will be carried out properly, it requires management support in the implementation of a five-moment hand hygiene culture, monitoring and evaluation for officers / staff through education and supervision involving the head of the room, nurses of PPI / IPCN / IPCLN and the hospital PPI committee.
\end{abstract}

Keywords: HAIs, Prevention and Control Programs

\begin{abstract}
ABSTRAK
Latar Belakang: Infeksi nosokomial atau Health-care Associated Infection (HAIs) yaitu infeksi yang didapatkan dan berkembang selama pasien dirawat di rumah sakit. Program HAIs/PPI penting untuk dilaksanakan sebagai tolok ukur mutu pelayanan juga melindungi pasien, petugas, pengunjung dan keluarga dari risiko tertularnya infeksi karena dirawat, bertugas dan berkunjung di rumah sakit atau fasilitas pelayanan kesehatan lainnya. Keputusan Menteri Kesehatan No. 129 Tentang Standar Pelayanan Minimal di Rumah Sakit dijelaskan bahwa standar kejadian infeksi nosokomial adalah $\leq 1,5 \%$, sedangkan angka kejadian infeksi (phlebitis) di rumah sakit melebihi standar yang telah ditetapkan karena berada di angka 6,9\%

Metode: Penelitian kualitatif dengan desain deskriptif studi kasus dengan jumlah informan sebanyak 4 (empat) informan yang diambil secara purposive sampling. Pengumpulan data dengan wawancara mendalam, observasi dan dokumentasi.

Hasil: Program HAIs yang telah dilakukan yaitu hand hygiene, surveilans risiko infeksi, asesmen berkala terhadap risiko, pelatihan PPI seperti hand hygiene campaign dan penggunaan alat pelindung diri (APD). Program hand hygiene compaign belum terlaksana dan kepatuhan cuci tangan oleh petugas belum mencapai standar yakni 100\%. Perlu penerapan budaya cuci tangan lima waktu atau five moment hand hygiene, pengawasan dan evaluasi bagi petugas/staf melalui edukasi dan supervisi yang dilakukan oleh kepala ruang, perawat PPI/IPCN/IPCLN dan komite PPI rumah sakit.
\end{abstract}

Kesimpulan: Program Pencegahan dan pengendalian HAIs akan terlaksana dengan baik diperlukan dukungan manajemen dalam penerapan budaya cuci tangan lima waktu atau five moment hand hygiene, perlu 
pengawasan dan evaluasi bagi petugas/staf melalui edukasi dan supervisi melibatkan kepala ruang, perawat PPI/IPCN/IPCLN dan komite PPI rumah sakit .

Kata kunci : HAIs, Program Pencegahan Dan Pengendalian

\section{PENDAHULUAN}

Rumah sakit sebagai salah satu sarana kesehatan yang memberikan pelayanan kesehatan kepada masyarakat memiliki peran yang sangat penting dalam meningkatkan derajat kesehatan masyarakat. Oleh karena itu rumah sakit dituntut untuk dapat memberikan pelayanan yang bermutu sesuai dengan standar yang sudah ditentukan (Kars, 2012). Rumah sakit merupakan sarana pelayanan kesehatan yang saat ini makin berkembang seiring dengan perkembangan ilmu pengetahuan dan teknologi di lain pihak rumah sakit dihadapi tantangan yang makin besar. Rumah sakit dituntut agar dapat memberikan pelayanan kesehatan yang bermutu, akuntabel dan transparan kepada masyarakat, khususnya bagi jaminan keselamatan pasien (patient safety). Untuk hal tersebut rumah sakit dan fasilitas pelayanan kesehatan lainnya yang ada di Indonesia perlu ditingkatkan pelayanannya khususnya dalam pencegahan dan pengendalian infeksi (Depkes RI., 2008).

Infeksi nosokomial baik di negara berkembang maupun negara maju saat ini merupakan salah satu penyebab meningkatnya angka kesakitan (morbidity) dan angka kematian (mortality) di rumah sakit, sehingga dapat menjadi masalah kesehatan baru dan menjadi salah satu penyebab semakin lama hari rawatan pada pasien rawat inap di rumah sakit dan fasilitas pelayanan kesehatan lainnya yang dapat meningkatkan biaya kesehatan. Saat ini, angka kejadian infeksi nosokomial telah dijadikan salah satu tolok ukur mutu pelayanan rumah sakit. Berdasarkan Kepmenkes Nomor 29 Tahun 2008, standar kejadian HAIs di rumah sakit sebesar $\leq 1,5 \%$. Izin operasional sebuah rumah sakit bisa dicabut karena tingginya angka kejadian infeksi nosokomial, bahkan pihak asuransi tidak mau membayar biaya yang ditimbulkan akibat infeksi nosokomial sehingga pihak penderita sangat dirugikan. (Darmadi, 2011)

Infeksi nosokomial (Hospital Acquired Infection) kini penyebutannya diubah menjadi infeksi terkait pelayanan kesehatan atau HAIs. Infeksi terkait pelayanan kesehatan (Healthcare Associated Infections) yang selanjutnya disingkat HAIs adalah infeksi yang terjadinya pada pasien selama perawatan di rumah sakit dan fasilitas pelayanan kesehatan lainnya dimana ketika masuk tidak ada infeksi dan tidak dalam masa inkubasi, termasuk infeksi dalam rumah sakit tapi muncul setelah pasien pulang, juga infeksi karena pekerjaan pada petugas rumah sakit dan tenaga kesehatan terkait proses pelayanan kesehatan di fasilitas pelayanan kesehatan. HAIs atau Healthcare Associated Infections dengan pengertian yang lebih luas, yaitu kejadian infeksi tidak hanya berasal dari rumah sakit, tetapi juga dapat dari fasilitas pelayanan kesehatan lainnya. Tidak terbatas infeksi kepada pasien namun dapat juga kepada petugas kesehatan dan pengunjung yang tertular pada saat berada di lingkungan fasilitas pelayanan kesehatan (PMK.27, 2017).

Penyakit infeksi terkait pelayanan kesehatan atau Healthcare Associated Infections (HAIs) merupakan salah satu masalah kesehatan di berbagai negara di dunia, termasuk Indonesia. Dalam forum Asian Pasific Economic Comitte (APEC) atau Global health Security Agenda (GHSA) penyakit infeksi terkait pelayanan kesehatan telah menjadi agenda yang dibahas. Hal ini menunjukkan bahwa HAIs yang ditimbulkan berdampak secara langsung sebagai beban ekonomi negara (PMK.27, 2017). Secara prinsip, kejadian HAIs sebenarnya dapat dicegah bila fasilitas pelayanan kesehatan secara konsisten melaksanakan program PPI. Pencegahan dan pengendalian infeksi merupakan upaya untuk memastikan perlindungan kepada setiap orang terhadap kemungkinan tertular infeksi dari 
sumber masyarakat umum dan disaat menerima pelayanan kesehatan pada berbagai fasilitas kesehatan (PMK.27, 2017).

Angka kejadian HAIs yang diperoleh dari berbagai sumber menunjukkan angka kejadian yang tinggi. Kejadian HAIs terjadi pada $15 \%$ dari semua pasien rawat inap. HAIs menjadi penyebab sekitar $4-56 \%$ penyebab kematian neonatus, dengan tingkat kejadian sekitar 75\% terjadi di Asia Tenggara dan Subsahara Afrika (World Health Organization., 2011). Berdasarkan hasil survei HAIs tahun 2014 di rumah sakit Amerika Serikat didapatkan angka kejadian HAIs mencapai 722.000 di unit perawatan akut dan 75.000 pasien dengan HAIs meninggal ketika dirawat di rumah sakit (Centers for Disease Control and Prevention., 2016).

Angka infeksi nosokomial terus meningkat mencapai sekitar 9\% (variasi 3-21\%) atau lebih dari 1,4 juta pasien rawat inap di rumah sakit seluruh dunia terkena infeksi nosokomial. Penelitian yang dilakukan oleh WHO menunjukkan bahwa sekitar 8,70\% dari 55 rumah sakit di 14 negara yang berada di Eropa, Timur Tengah, Asia Tenggara, dan Pasifik menunjukkan adanya HAIs. Prevalensi HAIs peling banyak di Mediterania timur dan Asia Tenggara yaitu sebesar 11,80\% dan 10\% sedangkan di Eropa dan Pasifik Barat masing-masing sebesar 7,70\% dan 9\% (Nurseha, 2013). Di Indonesia, HAIs mencapai $15,74 \%$ jauh di atas negara maju yang berkisar 4,8 - 15,5\% (Curtis et al., 2005). Data infeksi nosokomial di Indonesia dapat dilihat dari hasil survey point prevalensi dari 11 Rumah Sakit di DKI Jakarta yang dilakukan oleh Perdalin Jaya dan Rumah Sakit Penyakit Infeksi Prof. Dr. Sulianti Saroso Jakarta pada tahun 2003 didapatkan angka infeksi nosokomial untuk ILO (Infeksi Luka Operasi) 18,9\%, ISK (Infeksi Saluran Kemih) 15,1\%, IADP (Infeksi Aliran Darah Primer) 26,4\%, Pneumonia 24,5\% dan Infeksi Saluran Napas lain 15,1\%, serta Infeksi lain 32,1\% (Kemenkes RI, 2011). Penelitian yang dilakukan di 11 rumah sakit di DKI Jakarta pada tahun 2004 menunjukkan bahwa 9,80 pasien rawat inap mendapatkan infeksi nosokomial (HAIs). HAIs yang paling sering terjadi adalah infeksi daerah operasi (IDO), infeksi saluran kemih (ISK), infeksi saluran napas bawah (IADP) (Achmad, 2017).

Program pencegahan dan pengendalian infeksi merupakan sebuah program yang wajib dilaksanakan di setiap fasilitas pelayanan kesehatan di Indonesia (PMK.27, 2017). Kegiatan pencegahan dan pengendalian infeksi (PPI) di fasilitas pelayanan kesehatan merupakan suatu standar mutu pelayanan dan penting bagi pasien, petugas kesehatan maupun pengunjung. Pengendalian infeksi harus dilaksanakan oleh seluruh fasilitas pelayanan kesehatan untuk melindungi pasien, petugas kesehatan, dan pengunjung dari kejadian infeksi dengan memperhatikan cost effectiveness (Kars, 2012). Tujuan pengorganisasian program pencegahan dan pengendalian infeksi (PPI) adalah mengidentifikasi dan menurunkan risiko infeksi yang didapat serta ditularkan diantara pasien, staf, tenaga profesional kesehatan, tenaga kontrak, tenaga sukarela, mahasiswa, dan pengunjung (KARS, 2017). Upaya rumah sakit dalam melakukan manajemen pencegahan dan pengendalian infeksi terus dilakukan oleh pihak rumah sakit, karena pada dasarnya HAIs dapat dicegah bila fasilitas pelayanan kesehatan secara konsisten melaksanakan program PPI. Pencegahan dan pengendalian infeksi di fasilitas pelayanan kesehatan sangat penting bila terlebih dahulu petugas dan pengambil kebijakan memahami konsep dasar penyakit infeksi. Pedoman pencegahan dan pengendalian infeksi di fasilitas pelayanan kesehatan perlu disusun agar terwujud pelayanan kesehatan yang bermutu dan dapat menjadi acuan bagi semua pihak yang terlibat dalam pelaksanaan pencegahan dan pengendalian infeksi di dalam fasilitas pelayanan kesehatan serta dapat melindungi masyarakat dan mewujudkan patient safety yang pada akhirnya juga akan berdampak pada 
efisiensi pada manajemen fasilitas pelayanan kesehatan dan peningkatan kualitas pelayanan (Kars, 2012).

Angka infeksi HAIs pada rumah sakit di Indonesia mencapai 15,74\%. Di Yogyakarta insidensi terjadi infeksi nosokomial di sumah sakit secara umum sebesar 5,9\% (Widyanita \& Listiowati, 2014). Secara global hasil penelitian menunjukkan bahwa cuci tangan dapat menurunkan kejadian infeksi nosokomial sebesar 30\% (Sari \& Cahyawati, 2017).

Studi pendahuluan dilakukan di RS Nur Hidayah Yogyakarta dan diinformasikan bahwa kejadian Infeksi Daerah Operasi (IDO) tahun 2014 sampai dengan tahun 2019 secara garis trend menunjukkan angka penurunan. Standar Kementerian Kesehatan untuk kejadian HAIs di rumah sakit tidak boleh melebihi $1,5 \%$ dari total pasien yang dirawat atau dilakukan tindakan operasi. Pada grafik 1 tersebut yang masih perlu mendapatkan perhatian untuk angka kasus IDO di tahun 2014, tahun 2015 dan tahun 2018. Sedangkan kejadian IDO di tahun 2019 ada di angka 0,50\% dengan informasi data paling banyak terjadi pada pasien post appendiktomi berjumlah 6 (enam) pasien. Sedangkan kasus lainnya terjadi pada tindakan post operasi hernia, post orif, post operasi fam dan post operasi SC. Angka kejadian phlebitis terlihat ada penurunan yang signifikan. Pada bulan Januari 2019 sempat tinggi di angka 13\% dan terus menurun hingga pada bulan September 2019 di angka 6\%. Namun, secara pelaporan masih perlu dilakukan perbaikan. Karena pada tahun 2019, RS Nur Hidayah sedang dalam masa perbaikan struktur organisasi. Termasuk di dalamnya upaya melibatkan instalasi dalam program PPI. Namun dari hasil yang didapatkan di akhir tahun 2019 pelaporan di triwulan ke IV tidak terlaporkan. Hal ini karena struktur organisasi ada perubahan. Angka kepatuhan cuci tangan RS Nur Hidayah menunjukkan adanya penurunan. Selama tahun 2014 sampai 2019 belum sesuai dengan standar yang ditetapkan. Capaian tertinggi ada di tahun 2015, yaitu mencapai 82,5\%. Sedang di tahun tahun setelahnya terjadi penurunan. Tahun 2019 sendiri angka kepatuhan cuci tangan adalah 78,6\%. Kegiatan edukasi sudah dilakukan setiap kesempatan yang ada. Namun ketidakpatuhan masih sering dilakukan oleh petugas.

Menurut Keputusan Menteri Kesehatan No. 129 Tentang Standar Pelayanan Minimal di Rumah Sakit dijelaskan bahwa standar kejadian infeksi nosokomial adalah $\leq 1,5 \%$, untuk itu capaian angka kejadian phlebitis di RS Nur Hidayah melebihi standar yang telah ditetapkan karena berada di angka 6,9\% di tahun 2019. Mengingat pentingnya pencegahan dan pengendalian HAIs di rumah sakit, dan berdasarkan data surveilans di rumah sakit Nur Hidayah maka perlu adanya perbaikan dari berbagai aspek.

Program pencegahan dan pengendalian Healthcare Associated Infections (HAIs) di rumah sakit penting dilakukan dalam upaya keselamatan pasien (patient safety) di rumah sakit. Program HAIs/PPI akan efektif apabila mempunyai pimpinan yang ditetapkan, pelatihan dan pendidikan staf yang baik, metode untuk mengidentifikasi serta proaktif pada tempat berisiko infeksi, kebijakan dan prosedur yang memadai, juga melakukan koordinasi ke seluruh rumah sakit. Angka kejadian HAIs di Rumah Sakit Nur Hidayah Yogyakarta masih ditemukan dan masih tinggi diatas nilai standar pada kasus Phlebitis serta belum terlaporkannya kasus HAIs selain IDO dan Phlebitis yaitu kasus ISK dan IADP. Tujuan penelitian ini untuk mengetahui program pencegahan dan pengendalian Healthcare Association Infections (HAIs) di rumah sakit"

\section{METODE}

Penelitian ini merupakan penelitian kualitatif dengan desain deskriptif studi kasus. Penelitian kualitatif adalah penelitian yang bermaksud untuk memahami fenomena tentang apa yang dialami oleh subjek penelitian misalnya perilaku, persepsi, motivasi, tindakan, 
secara holistik, dan dengan cara deskripsi dalam bentuk kata-kata dan bahasa, pada suatu konteks khusus yang alamiah dan dengan memanfaatkan berbagai metode alamiah (Moleong, 2013). Penelitian dilakukan bulan Januari sampai dengan Februari 2020 di Rumah Sakit Nur Hidayah. Variabel tunggal yaitu program pencegahan dan pengendalian Healthcare Associated Infections (HAIs) rumah sakit. Defini operasional program pencegahan dan pengendalian infeksi adalah adalah upaya untuk mencegah dan meminimalkan terjadinya infeksi pada pasien, petugas, pengunjung, dan masyarakat sekitar fasilitas pelayanan kesehatan. Fokus penelitian pada program dan bukti pelaksanaan program PPI. Purposive sampling adalah teknik pengambilan sampel sumber data dengan pertimbangan tertentu. Dengan subjek penelitian dari unsur atasan yaitu Direktur Rumah Sakit, Ketua Komite PPI, unsur bawahan yaitu Staf. Obyek penelitian ini adalah program pencegahan dan pengendalian Healthcare Associated Infections (HAIs). Teknik pengumpulan data dapat dilakukan dengan pengamatan, wawancara, dan dokumentasi. Keabsahan data menggunakan trianggulasi sumber dan trianggulasi teknik. Metode analisis data menggunakan Reduksi Data), Penyajian Data dan verifikasi.

\section{HASIL DAN PEMBAHASAN}

Program pencegahan dan pengendalian infeksi ada tiga hal yang ditanyakan oleh peneliti yang meliputi implementasi program PPI, kegiatan assesmen risiko, dan pelaksanaan surveilans yang disajikan dalam tabel 1 berikut:

Tabel 1. Hasil Wawancara Tentang Program Pencegahan dan Pengendalian HAIs di Rumah Sakit X

\begin{tabular}{|c|c|c|c|c|c|}
\hline \multirow{2}{*}{ No } & \multirow{2}{*}{ Pertanyaan } & \multicolumn{4}{|c|}{ Jawaban } \\
\hline & & Informan 1 & Informan 2 & Informan 3 & Informan 4 \\
\hline 1. & $\begin{array}{l}\text { Bagaimana } \\
\text { implementasi } \\
\text { program PPI dan } \\
\text { kesehatan kerja untuk } \\
\text { menurunkan risiko } \\
\text { infeksi terkait } \\
\text { pelayanan kesehatan } \\
\text { pada pasien? }\end{array}$ & $\begin{array}{l}\text { Ada manajemen } \\
\text { risiko, } \\
\text { kelengkapan APD, } \\
\text { five moment hand } \\
\text { hygiene }\end{array}$ & $\begin{array}{l}\begin{array}{l}\text { Program hand } \\
\text { hygiene dan } \\
\text { pemakaian } \\
\text { APD yang } \\
\text { lengkap }\end{array} \\
\end{array}$ & $\begin{array}{lr}\text { Program } & \text { yang } \\
\text { sudah berjalan } \\
\text { banyak, misalnya } \\
\text { ketepatan } \text { APD } \\
\text { dan cuci tangan } \\
\text { namun program } \\
\text { hand hygiene } \\
\text { campaign belum } \\
\text { terlaksana dengan } \\
\text { baik }\end{array}$ & $\begin{array}{l}\text { Pelatihan hand } \\
\text { hygiene } \\
\text { karyawan dan } \\
\text { pasien, } \\
\text { penggunaan } \\
\text { APD yang benar }\end{array}$ \\
\hline 2. & \begin{tabular}{lrr} 
Apakah ada & bukti \\
rumah sakit secara \\
proaktif melakukan \\
assesmen risiko \\
infeksi paling sedikit \\
\multicolumn{2}{l}{ setahun sekali? } \\
\end{tabular} & Ada & Ada & Ada & Ada \\
\hline 3. & \begin{tabular}{lr}
\multicolumn{2}{l}{ Diminta menjelaskan } \\
alur hasil dari \\
assesment \\
infeksi?
\end{tabular} & $\begin{array}{l}\text { Menjelaskan } \\
\text { tentang alur hasil } \\
\text { dari assesmen } \\
\text { risiko dan tindak } \\
\text { lanjutnya }\end{array}$ & \begin{tabular}{lr}
\multicolumn{2}{l}{ Menjelaskan } \\
tentang alur \\
hasil rari \\
assesmen risiko \\
dan tindak \\
lanjutnya
\end{tabular} & $\begin{array}{l}\text { Menjelaskan } \\
\text { tentang alur hasil } \\
\text { dari assesmen } \\
\text { risiko dan tindak } \\
\text { lanjutnya }\end{array}$ & \begin{tabular}{lr}
\multicolumn{2}{l}{ Menjelaskan } \\
tentang alur \\
hasil & dari \\
assesmen & risiko \\
dan & tindak \\
lanjutnya & \\
\end{tabular} \\
\hline 4. & $\begin{array}{l}\text { Bagaimana } \\
\text { pelaksanaan } \\
\text { surveilans di bangsal } \\
\text { bedah, apakah ada } \\
\text { kendala? }\end{array}$ & $\begin{array}{lr}\text { Surveilans } & \text { sudah } \\
\text { berjalan } & \text { tetapi } \\
\text { SDM masih perlu } \\
\text { ditertibkan untuk } \\
\text { pelaporan }\end{array}$ & $\begin{array}{l}\text { Surveilans } \\
\text { belum terlalu } \\
\text { jalan, } \\
\text { terkendala pada } \\
\text { tim dan SDM. } \\
\text { Surveilans } \\
\text { angka inos tetap } \\
\text { ada laporan } \\
\text { perbulan } \\
\text { melalui IPCN }\end{array}$ & $\begin{array}{l}\text { SDM belum tertib } \\
\text { melaporkan ke } \\
\text { IPCN. Kendala } \\
\text { pada staf perawat } \\
\text { karena beban } \\
\text { tugas }\end{array}$ & $\begin{array}{l}\text { Ada kendala, } \\
\text { tidak tertib } \\
\text { dalam pelaporan } \\
\text { harian. } \\
\text { Pelaporan dari } \\
\text { IPCLN ke IPCN } \\
\text { belum tertib }\end{array}$ \\
\hline
\end{tabular}




\begin{tabular}{|c|c|c|c|c|c|c|c|c|c|}
\hline \multirow{2}{*}{ No } & \multirow{2}{*}{\multicolumn{2}{|c|}{ Pertanyaan }} & \multicolumn{7}{|c|}{ Jawaban } \\
\hline & & & \multicolumn{2}{|c|}{ Informan 1} & \multirow{2}{*}{\multicolumn{2}{|c|}{\begin{tabular}{ll}
\multicolumn{2}{c}{ Informan 2} \\
Monitoring & dan \\
evaluasi & dari \\
IPCN. & Ada \\
laporan & tiap
\end{tabular}}} & \multicolumn{2}{|c|}{ Informan 3} & \multirow{2}{*}{\begin{tabular}{ll}
\multicolumn{2}{c}{ Informan 4} \\
Monitoring dan \\
evaluasi dari \\
IPCN yang \\
melakukan
\end{tabular}} \\
\hline 5. & $\begin{array}{l}\text { Bagaimana } \\
\text { monitoring } \\
\text { evaluasi } \\
\text { surveilans? }\end{array}$ & $\begin{array}{r}\text { dan } \\
\text { untuk }\end{array}$ & $\begin{array}{l}\text { Monitoring } \\
\text { evaluasi } \\
\text { IPCN } \\
\text { dilakukan } \\
\text { kontinyu }\end{array}$ & $\begin{array}{r}\text { dan } \\
\text { oleh } \\
\text { sudah } \\
\text { secara }\end{array}$ & & & $\begin{array}{l}\text { Edukasi } \\
\text { IPCN } \\
\text { menertibkan } \\
\text { laporan }\end{array}$ & $\begin{array}{r}\text { dari } \\
\text { untuk }\end{array}$ & \\
\hline
\end{tabular}

Rangkuman hasil analisis wawancara pada tabel 1 tentang program pencegahan dan pengendalian HAIs dapat diinformasikan bahwa keempat informan memahami implementasi program PPI untuk menurunkan risiko infeksi terkait pelayanan kesehatan pada pasien yang meliputi adanya manajemen risiko, program hand hygiene dan penggunaan alat pelindung diri (APD).

Rumah sakit Nur Hidayah telah melakukan assesmen risiko dengan alur yang telah dijelaskan oleh dua informan diatas. Untuk pelaksanaan surveilans di ruang rawat inap bedah masih terkendala pada SDM yang belum tertib melaporkan hasil surveilans kepada IPCN, terbukti dari kutipan salah satu hasil wawancara berikut:

"Ya banyak kendalanya, kadang pelaporan itu banyak yang nggak lapor semisal ada kejadian phlebitis atau apa jarang dilaporkan, jadi kalau nggak dioyak-oyak atau nggak diaktifkan gitu lo mbak, nggak diingatkan kembali ya nggak jalan. Mungkin karena beban tugas perawat ngurusin pasien untuk lapor itu kan kadang jadi budaya lapor itu belum ada”. Informan 3.

Kegiatan monitoring dan evaluasi telah dilaksanakan oleh perawat IPCN melalui edukasi kepada staf untuk menertibkan laporan. Simpulan hasil wawancara petugas tentang program pencegahan dan pengendalian HAIs di ruang rawat inap bedah RS Nur Hidayah adalah secara umum program PPIRS sudah terlaksana dengan baik, namun untuk program surveilans dan hand hygiene campaign masih perlu perbaikan. Kendala program surveilans adalah masih rendahnya budaya lapor petugas sedangkan program hand hygiene campaign belum terlaksana sesuai target dikarenakan adanya kendala kegiatan rumah sakit yang bertumpuk tiap bulan.

Setelah melakukan wawancara kepada petugas, peneliti melakukan observasi dan telusur dokumen terkait program Pencegahan dan Pengendalian HAIs di Ruang Rawat Inap Bedah RS Nur Hidayah. Dalam kegiatan observasi dan telusur dokumentasi ini dilakukan dengan tujuan untuk mengetahui bukti pelatihan PPI termasuk pelatihan cuci tangan 6 (enam) langkah 5 (lima) moment yang sudah dilaksanakan dan mengetahui bukti kegiatan asesmen risiko yang telah dilakukan oleh Komite PPI rumah sakit.

Tabel 2. Hasil Analisis Observasi Tentang Pelaksanaan Program HAIs/PPI Rumah Sakit Dalam Upaya Pencegahan dan Pengendalian HAIs di Rumah Sakit X

\begin{tabular}{ccc}
\hline No & Hasil Observasi & Keterangan \\
\hline 1. & Pelatihan cuci tangan 6 langkah 5 moment \& & terlaksana \\
\hline 2. & Pelatihan penggunaan APD & terlaksana \\
\hline 3. & Bukti hasil tindak lanjut asesmen risiko di tahun 2019 & terlaksana \\
\hline
\end{tabular}

Program Pencegahan dan Pengendalian HAIs di rumah sakit sudah dilaksanakan melalui kegiatan Pelatihan cuci tangan 6 langkah 5 moment \& Pelatihan penggunaan APD bagi petugas rumah sakit. Kemudian diinformasikan juga bahwa rumah sakit sudah 
melakukan tindak lanjut hasil asesmen risiko dari hasil kegiatan surveilans PPI di tahun 2019. Dalam hasil asesmen risiko tersebut dilaporkan bahwa masih tingginya kepatuhan kebersihan tangan petugas belum sesuai standar, tidak terlaksananya pemakaian APD oleh petugas juga masih tinggi serta belum tersedianya ruang isolasi khusus pasien infeksius di rumah sakit.

Disimpulkan bahwa pada aspek pelaksanaan program HAIs/PPI dalam mendukung pelaksanaan upaya pencegahan dan pengendalian HAIs di ruang rawat inap bedah RS Nur Hidayah belum berjalan dengan baik, program sudah ada dan sudah dilaksanakan namun masih ditemukan adanya ketidakpatuhan petugas dalam membudayakan cuci tangan dan penggunaan APD.

FGD (Focus Group Discussion) adalah cara yang digunakan untuk mengetahui pendapat dan tanggapan petugas dalam mengetahui kendala pelaksanaan sistem identifikasi pasien. Berdasarkan temuan hasil penelitian peneliti melakukan wawancara khusus kepada petugas perawat bangsal, kepala ruang rawat inap bedah, dan perawat IPCN dengan memberi pertanyaan terkait beberapa hal yang menjadi kendala dalam pelaksanaan program PPI berdasarkan hasil observasi yang dilakukan peneliti.

Tabel 3. Hasil Foccus Group Discussion (FGD) Terkait Kendala Pelaksanaan Program Pencegahan dan Pengendalian HAIs di Rumah Sakit X

\begin{tabular}{|c|c|c|c|c|c|}
\hline \multirow[t]{2}{*}{ No } & \multirow[t]{2}{*}{ Permasalahan } & \multicolumn{4}{|c|}{$\begin{array}{l}\text { JAWABAN INFORMAN TENTANG PENYEBAB DARI } \\
\text { PERMASALAHAN }\end{array}$} \\
\hline & & 1 & 2 & 3 & 4 \\
\hline 1. & $\begin{array}{l}\text { Program PPI } \\
\text { yakni hand } \\
\text { hygiene campaign } \\
\text { belum terlaksana } \\
\text { dengan baik }\end{array}$ & $\begin{array}{l}\text { Keterbatasan } \\
\text { waktu, belum } \\
\text { dapat } \\
\text { dilaksanakan } \\
\text { secara rutin }\end{array}$ & Keterbatasan waktu & $\begin{array}{l}\text { Volume } \\
\text { pekerjaan yang } \\
\text { tinggi, belum } \\
\text { dapat } \\
\text { dilaksanakan } \\
\text { secara rutin }\end{array}$ & $\begin{array}{l}\text { Perlu dukungan/ } \\
\text { partisipasi } \\
\text { manajemen dalam } \\
\text { pelaksanaan } \\
\text { supervise program } \\
\text { dan evaluasi jumlah } \\
\text { tenaga }\end{array}$ \\
\hline 2. & $\begin{array}{l}\text { Ketidakpatuhan } \\
\text { petugas dalam } \\
\text { membudayakan } \\
\text { cuci tangan dan } \\
\text { penggunaan APD }\end{array}$ & $\begin{array}{l}\text { Kesadaran } \\
\text { petugas yang } \\
\text { kurang, perlu } \\
\text { keterlibatan } \\
\text { kepala } \\
\text { ruang/perawat } \\
\text { PPI }\end{array}$ & $\begin{array}{l}\text { Kesadaran petugas } \\
\text { yang kurang. Perlu } \\
\text { sosialisasi dan } \\
\text { kegiatan pendidikan } \\
\text { pelatihan petugas } \\
\text { serta dukungan } \\
\text { IPCLN }\end{array}$ & $\begin{array}{l}\text { Kesadaran } \\
\text { petugas yang } \\
\text { kurang akan } \\
\text { hand hygiene. } \\
\text { Perlu } \\
\text { keterlibatan } \\
\text { kepala ruangan }\end{array}$ & $\begin{array}{lc}\begin{array}{l}\text { Kesadaran } \\
\text { yang }\end{array} & \text { ketugas } \\
\text { Keterlibatan } & \text { kepala } \\
\text { ruang dan IPCLN }\end{array}$ \\
\hline
\end{tabular}

\section{INTERPRESTASI}

Program PPI terkait hand hygiene campaign belum terlaksana dengan baik dikarenakan adanya keterbatasan waktu petugas dengan volume pekerjaan yang tinggi sehingga belum dapat terlaksana dengan baik. Diperlukan dukungan atau partisipasi dari pimpinan atau manajemen untuk tetap memberikan semangat/support atau dukungan dengan penyediaan jumlah tenaga/petugas yang sesuai dan supervise program. Ketidakpatuhan petugas dalam membudayakan cuci tangan dan penggunaan APD diakui karena tingkat kesadaran petugas yang kurang akan pentingnya cuci tangan dan penggunaan APD saat memberikan pelayanan kepada pasien. Diperlukan adanya keterlibatan kepala ruang atau perawat PPI (IPCLN) yang mengawasi pelaksanaan kepatuhan petugas akan cuci tangan.

Berdasarkan tabel 3 hasil rangkuman FGD terkait kendala pelaksanaan upaya pencegahan dan pengendalian HAIs di rumah sakit diinformasikan bahwa belum terlaksananya Program PPI yaitu pelaksanaan hand hygiene campaign dikarenakan keterbatasan waktu yang dimiliki petugas saat memberikan pelayanan yang dikarenakan volume pekerjaan yang cukup tinggi sehingga belum tertib dalam melaksanakan program 
kampanye cuci tangan atau hand hygiene campaign. Petugas tetap berupaya mendukung dan berpartisipasi dalam program hand hygiene campaign yang ada di rumah sakit. Ketidakpatuhan petugas dalam membudayakan cuci tangan dan ketidakpatuhan petugas dalam penggunaan Alat Pelindung Diri (APD) saat melakukan pelayanan atau tindakan kepada pasien terjadi dikarenakan karena kesadaran petugas yang kurang akan budaya cuci tangan dan budaya pemakaian APD dalam memberikan pelayanan.

Program pengendalian infeksi nosokomial merupakan salah satu pilar utama mutu layanan kesehatan. Definisi infeksi nosokomial atau yang sekarang disebut sebagai Healthcare Associated Infection (HAIs) menurut WHO adalah infeksi yang didapatkan dan berkembang selama pasien dirawat di rumah sakit. (Depkes, 2008) Program Pencegahan dan Pengendalian Infeksi (PPI) sangat penting untuk dilaksanakan di Rumah Sakit dan Fasilitas Pelayanan Kesehatan lainnya sebagai tempat pelayanan kesehatan disamping sebagai tolak ukur mutu pelayanan juga untuk melindungi pasien, petugas juga pengunjung dan keluarga dari risiko tertularnya infeksi karena dirawat, bertugas dan berkunjung ke suatu rumah sakit atau fasilitas pelayanan kesehatan lainnya. (Depkes RI., 2008)

Tujuan pengorganisasian program pencegahan dan pengendalian infeksi (PPI) adalah mengidentifikasi dan menurunkan risiko infeksi yang didapat serta ditularkan diantara pasien, staf, tenaga profesional kesehatan, tenaga kontrak, tenaga sukarela, mahasiswa, dan pengunjung (KARS, 2017). Program PPI efektif jika program dilaksanakan secara komprehensif meliputi seluruh unit maupun individu yang berada di rumah sakit. Program PPI juga mencakup upaya kesehatan kerja, melakukan identifikasi, dan menangani masalah-masalah infeksi yang sangat penting bagi rumah sakit dari segi epidemiologik. Program PPI juga membutuhkan berbagai strategi yang mencakup semua tingkat unit atau layanan berdasar atas ukuran rumah sakit, lokasi geografik, layanan dan pasien. (KARS, 2017)

Rumah Sakit Nur Hidayah telah menjalankan program pencegahan dan pengendalian infeksi (PPI) seperti hand hygiene, surveilans risiko infeksi, asesmen berkala terhadap risiko, pelatihan PPI seperti hand hygiene compaign dan penggunaan alat pelindung diri (APD). Untuk program hand hygiene compaign belum terlaksana sesuai target yang ditetapkan rumah sakit yakni sebulan sekali. Dalam pelaksaannya, kepatuhan cuci tangan oleh petugas belum mencapai standar yakni $100 \%$. Untuk mewujudkan budaya cuci tangan lima waktu atau five moment hand hygiene, rumah sakit harus melaksanakan pengawasan dan evaluasi bagi petugas/staf melalui edukasi dan supervisi yang dilakukan oleh kepala ruang dan komite PPI rumah sakit. Beberapa penelitian telah membuktikan bahwa peran supervisi sangat mendorong peningkatan perilaku cuci tangan oleh petugas/staf melalui edukasi dan bimbingan. Menurut penelitian Ponco, et al (2016) perlu dilakukan pelaksanaan supervisi yang kontinyu dan berkesinambungan, serta diperlukan pelatihan tentang supervisi secara terprogram dan berkelanjutan. Menurut penelitian Banjarnahor (2016), pengawasan Infection Prevention and Control Link Nurse (IPCLN) memiliki hubungan yang signifikan terhadap kepatuhan perawat melakukan cuci tangan di ruang rawat inap. Menurutnya, perlu mengoptimalkan peran Infection Prevention and Control Link Nurse (IPCLN) untuk meningkatkan kepatuhan cuci tangan perawat dan pelaksanaan program pencegahan dan pengendalian infeksi lainnya.

Program pencegahan dan pengendalian infeksi (PPI) merupakan sebuah program yang wajib dilaksanakan disetiap fasilitas pelayanan kesehatan di Indonesia untuk meminimalisir risiko penyebaran infeksi. Selain peran teknis, faktor manajemen merupakan unsur yang diperlukan dalam keberhasilan program pencegahan dan pengendalian infeksi di rumah sakit. Pencegahan dan pengendalian infeksi di rumah sakit termasuk didalamnya adalah hand hygiene yang merupakan salah satu komponen penting 
kejadian infeksi dapat dicegah sebagai indikator mutu pelayanan di rumah sakit (Wahyuni, dkk. 2020).

Kegiatan surveilans di Rumah Sakit Nur Hidayah sudah berjalan, namun dalam pelaksanannya petugas masih harus dimotivasi dan diingatkan untuk lebih tertib dalam pelaporannya. Rumah sakit harus melakukan surveilans infeksi berdasar atas data epidemiologis yang penting dan berfokus pada daerah infeksi, penggunaan peralatan, prosedur serta praktik untuk mencegah dan menurunkan angka infeksi. Surveilans berdasar atas risiko secara proaktif dapat digunakan untuk identifikasi risiko infeksi dan program berfokus pada daerah infeksi. Selanjutnya, dengan surveilans dikumpulkan data dan analisisnya untuk membuat asesmen risiko (KARS. 2017).

\section{KESIMPULAN}

Program pencegahan dan pengendalian infeksi (PPI) di rumah sakit yang sudah dilaksanakan adalah hand hygiene, surveilans risiko infeksi, asesmen berkala terhadap risiko, pelatihan PPI seperti hand hygiene compaign dan penggunaan alat pelindung diri (APD). Program hand hygiene compaign belum terlaksana sesuai target yang ditetapkan rumah sakit yakni sebulan sekali. Dalam pelaksaannya, kepatuhan cuci tangan oleh petugas belum mencapai standar yakni $100 \%$. Untuk mewujudkannya perlu penerapan budaya cuci tangan lima waktu atau five moment hand hygiene, rumah sakit harus melaksanakan pengawasan dan evaluasi bagi petugas/staf melalui edukasi dan supervisi yang dilakukan oleh kepala ruang, perawat PPI/IPCN/IPCLN dan komite PPI rumah sakit.

\section{SARAN}

Budaya cuci tangan dan pemakaian APD melalui survey budaya, pembuatan buku saku atau banner tentang standar keselamatan pasien terutama petunjuk teknis 6 (enam) langkah 5 (lima) momen cuci tangan dan pemakaian APD, atau adakan kegiatan lomba antar ruangan/antar petugas rumah sakit serta lakukan sosialisasi tentang topic cuci tangan yang benar dan pemakaian APD yang tepat.

\section{DAFTAR PUSTAKA}

Achmad, I. (2017). Manajemen Perawatan Pasien Total Care Dan Kejadian Infeksi Nosokomial Di Ruang Icu Rsud Masohi Tahun 2016. Global Health Science.

Ain, A., \& Siulina, M. (2018). Hubungan Kepatuhan Perawat Mencuci Tangan Dengan Kejadian HAIs (Flebitis) Di Rumah Sakit Dirgahayu Samarinda. Jurnal Medika: Karya Ilmiah Kesehatan, 1(1).

Ayunda, T. (2019). Kebijakan Pencegahan Dan Pengendalian Infeksi Untuk Meningkatkan Standar Akriditasi Rumah Sakit.

Azwar, Saifuddin. 2015. Metode Penelitian. Yogyakarta : Pustaka Pelajar

Banjarnahor, S. (2018). Hubungan Pengawasan Infection Prevention And Control Link Nurse (Ipcln) Terhadap Kepatuhan Perawat Melakukan Cuci Tangan Di Ruang Rawat Inap Murni Teguh Memorial Hospital Medan. Indonesian Trust Health Journal, 1(1), 1-1.

Centers for Disease Control and Prevention. (2016). National and State Associated Infections Progress Report. Centers for Disease Control and Prevention.

Curtis, V., Scott, B., \& Cardosi, J. (2005). The handwashing handbook; A guide for developing a hygiene promotion program to increase handwashing with soap. World Bank. 
Darmadi. (2011). nfeksi Nosokomial: Problematika \& Pengendaliannya. In Infeksi Nosokomial: Problematika \& Pengendaliannya.

Departemen Kesehatan Republik Indonesia. 2018. Pedoman Manajerial Pencegahan dan Pengendalian Infeksi di Rumah Sakit dan Fasilitas Pelayanan Kesehatan Lainnya. Jakarta: Departemen Kesehatan RI.

Djohan, Agustinus Johanes, Devy Halim. 2013. Pengelolaan Limbah Rumah Sakit. Jakarta: Salemba Medika.

Gahayu, Sri Asih. 2016. Penelitian Kualitatif Bidang Kesehatan Masyarakat. Yogyakarta : Deepublish.

Ginting, D., Fentiana, N., Rajagukguk, T., \& Wahyudi, H. (2019). Gaya Kepemimpinan dan Komitmen Paramedis dalam Implementasi Akreditasi Rumah Sakit Versi SNARS. Jurnal Ilmiah Universitas Batanghari Jambi, 19(3), 504-508.

INFEKSI, P. D. P. (2008). Pedoman manajerial pencegahan dan pengendalian infeksi di rumah sakit dan fasilitas pelayanan kesehatan lainnya.

Kars. (2012). Komisi Akreditasi Rumah Sakit. Kars.

KARS. (2017). Standar Nasional Akreditasi Rumah Sakit Efektif 1 Januari 2018. Standar Nasional Akreditasi Rumah Sakit.

Notoatmodjo, Soekidjo. 2012. Metodologi Penelitian Kesehatan. Jakarta : Rineka Cipta.

Nurseha, D. (Poltekkes M. J. K. (2013). Pengembangan Tindakan Pencegahan Infeksi Nosokomial oleh Perawat di Rumah Sakit Berbasis Health Belief Model. Jurnal Ners.

Nurseha, E., Haryanto, I., \& Torina, D. T. (2017). Pelaksanaan Higiene Penjamah Makanan Dan Sanitasi Lingkungan Di Instalasi Gizi Rumah Sakit Holistic Purwakarta Tahun 2016. Journal of Holistic and Health Sciences, 1(1), 26-39.

Pasaribu, D. A. (2019). Hubungan Pengawasan Perawat IPCN (Infection Prevention Control Nurse) Dengan Kepatuhan Perawat Membuang Sampah Medis Dan Non Medis di RSUD Padang Lawas. Journal of Midwifery and Nursing, 1(2 April), 15-19.

PMK.27. (2017). PERATURAN MENTERI KESEHATAN REPUBLIK INDONESIA NOMOR 27 TAHUN 2017 TENTANG PEDOMAN PENCEGAHAN DAN PENGENDALIAN INFEKSI DI FASILITAS PELAYANAN KESEHATAN. In Progress in Physical Geography.

Ponco, S. H., \& Faridah, V. N. (2016). Penerapan Supervisi Klinis Kepala Ruang Untuk Meningkatkan Pelaksanaan Cuci Tangan Lima Momen Perawat Pelaksana.

Sapardi, V. S., Machmud, R., \& Gusty, R. P. (2018). Analisis Pelaksanaan Manajemen Pencegahan Dan Pengendalian Healthcare Associated Infections Di RSI Ibnusina. Jurnal Endurance, 3(2), 358-366.

Sari, D. R., \& Cahyawati, F. E. (2017). Hubungan pengetahuan petugas kesehatan Dengan perilaku five moment for hand Hygiene di rumah sakit PKU Muhammadiyah Gamping (Doctoral dissertation, Universitas' Aisyiyah Yogyakarta). 
Septiari. 2012. Infeksi Nosokomial. Yogyakarta : Nuha Medika.

Siregar, I. R. (2018). Analisis Pelaksanaan Upaya Promotif dan Preventif Tentang Healthcare Associated Infections (HAIs) di Rumah Sakit Tingkat IV Pematangsiantar. Skripsi, Universitas Sumatera Utara.

Sugiono. 2012. Metode Penelitian Kuantitatif, Kualitatif R \& D. Bandung : Alfabeta

Suyatmi, S., Suprihanto, J., \& Akhmad, J. (2018). Analisis Pelaksanaan Pencegahan Dan Pengendalian Infeksi Di Puskesmas Prembun Kebumen. Tesis, STIE Widya Wiwaha.

Undang Undang No 44 Tentang Rumah Sakit, 1 Presiden RI 2 (2009). https://kesmas.kemkes.go.id/perpu/konten/uu/uu-nomor-44-tahun-2009-ttg-rs

Wahyuni, T., Hasnita, E., \& Suwito, A. (2020). Analisis Faktor Pelaksanaan Program Pencegahan Dan Pengendalian Infeksi (Ppi) Di Rsud Kota Padang Panjang Tahun 2019. Human Care Journal, 5(3), 845-853.

Widyanita, A., \& Listiowati, E. (2014). HUBUNGAN TINGKAT PENGETAHUAN HAND HYGIENE DENGAN KEPATUHAN PELAKSANAAN HAND HYGIENE PADA PESERTA PROGRAM PENDIDIKAN PROFESI DOKTER. Biomedika. https://doi.org/10.23917/biomedika.v6i1.281

World Health Organization. (2011). The burden of health care-associated infection worldwide. Infection Prevention and Control. 